\title{
The horizontal resolution of MIPAS
}

\author{
T. von Clarmann ${ }^{1}$, C. De Clercq ${ }^{2}$, M. Ridolfi ${ }^{3}$, M. Höpfner ${ }^{1}$, and J.-C. Lambert ${ }^{2}$ \\ ${ }^{1}$ Forschungszentrum Karlsruhe, Institut für Meteorologie und Klimaforschung, Karlsruhe, Germany \\ ${ }^{2}$ Belgian Institute for Space Aeronomy (IASB-BIRA), Brussels, Belgium \\ ${ }^{3}$ Dipartimento di Chimica Fisica e Inorganica, Università di Bologna, Italy
}

Received: 1 September 2008 - Published in Atmos. Meas. Tech. Discuss.: 6 October 2008

Revised: 13 February 2009 - Accepted: 15 February 2009 - Published: 18 February 2009

\begin{abstract}
Limb remote sensing from space provides atmospheric composition measurements at high vertical resolution while the information is smeared in the horizontal domain. The horizontal components of two-dimensional (altitude and along-track coordinate) averaging kernels of a limb retrieval constrained to horizontal homogeneity can be used to estimate the horizontal resolution of limb retrievals. This is useful for comparisons of measured data with modeled data, to construct horizontal observation operators in data assimilation applications or when measurements of different horizontal resolution are intercompared. We present these averaging kernels for retrievals of temperature, $\mathrm{H}_{2} \mathrm{O}, \mathrm{O}_{3}, \mathrm{CH}_{4}, \mathrm{~N}_{2} \mathrm{O}$, $\mathrm{HNO}_{3}$ and $\mathrm{NO}_{2}$ from MIPAS (Michelson Interferometer for Passive Atmospheric Sounding) high-resolution limb emission spectra. The horizontal smearing of a MIPAS retrieval in terms of full width at half maximum of the rows of the horizontal averaging kernel matrix varies typically between about 200 and $350 \mathrm{~km}$ for most species, altitudes and atmospheric conditions. The range where $95 \%$ of the information originates from varies from about 260 to $440 \mathrm{~km}$ for these cases. This information spread is smaller than the MIPAS horizontal sampling, i.e. MIPAS data are horizontally undersampled, and the effective horizontal resolution is driven by the sampling rather than the smearing. The point where the majority of the information originates from is displaced from the tangent point towards the satellite by typically less than $10 \mathrm{~km}$ for trace gas profiles and about 50 to $100 \mathrm{~km}$ for temperature, with a few exceptions for uppermost altitudes. The geolocation of a MIPAS profile is defined as the tangent point of the middle line of sight in a MIPAS limb scan. The majority of the information displacement with respect to this nominal geolocation of the measurement is caused by the satellite movement and the geometrical displacement of the actual tangent point as a function of the elevation angle.
\end{abstract}

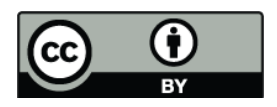

Correspondence to: T. von Clarmann (thomas.clarmann@imk.fzk.de)

\section{Introduction}

Typical limb sounding retrieval schemes assume local horizontal homogeneity of the atmosphere, i.e., vertical profiles of atmospheric state variables are retrieved under the (usually hard-wired) assumption that the atmosphere seen during one limb scan varies only with altitude but not in the horizontal domain (e.g., McKee et al., 1969; Mill and Drayson, 1978; Goldman and Saunders, 1979; Carlotti, 1988; Ridolfi et al., 2000; von Clarmann et al., 2003; Raspollini et al., 2006). Because of horizontal variations of the real atmospheric state, this assumption causes a so-called smoothing error (Rodgers, 2000) and affects the horizontal resolution of the limb measurement. This horizontal smoothing must be considered in quantitative applications, e.g. in comparisons of measurements with modeled data, data assimilation (e.g., Lahoz et al., 2007), whenever the model grid is significantly finer than the horizontal resolution of the measurement. Similar considerations apply to the intercomparison of measurements of different horizontal resolution (e.g., Ridolfi et al., 2007). In this paper we present a set of horizontal averaging kernels for Michelson Interferometer for Passive Atmospheric Sounding (MIPAS) (Fischer et al., 2008). These averaging kernels characterize the horizontal response of the retrieval to a delta perturbation of the true atmospheric state (Rodgers, 2000). In particular, they can be used to construct horizontal observation operators (c.f., Ide et al., 1997).

\section{MIPAS measurements and retrievals}

MIPAS is an infrared limb emission sounder on Envisat, designed and operated for measurements of constituents between the upper troposphere and the mesosphere. MIPAS is a rear looking instrument with the lines of sight approximately in the orbit plane. In the original measurement mode, which was operational from July 2002 to March 2004, 17 tangent altitudes between 6 and $68 \mathrm{~km}$ were measured per limb scan. The altitude of the Envisat orbit is about $800 \mathrm{~km}$,

Published by Copernicus Publications on behalf of the European Geosciences Union. 
and the ground track speed is about $510 \mathrm{~km}$ per $76.5 \mathrm{~s}$ which are needed to record one full limb scan. The field of view covers about $3 \mathrm{~km}$ in altitude at the tangent point. The horizontal extension of the field of view is about $30 \mathrm{~km}$ at the tangent point. While the latter number indicates the horizontal extension of the air mass sampled by MIPAS, it is not adequate to talk about cross-track resolution here, because there is no instantaneous cross-track sampling.

The operational MIPAS level-2 processor (Ridolfi et al., 2000; Raspollini et al., 2006) performs a maximum likelihood profile retrieval (Rodgers, 2000) of temperature and trace species abundance profiles using an unconstrained global fit approach (Carlotti, 1988). As usual in limb sounding, horizontal homogeneity of the atmosphere is assumed. The vector $\boldsymbol{y}$ contains those measurements of a MIPAS limb scan which are actually used for the retrieval (Dudhia et al., 2002; Raspollini et al., 2006) of the vertical profile $\boldsymbol{x}$ of the target variable, sampled at the tangent altitudes of the limb measurements, $\boldsymbol{K}$ is the Jacobian matrix containing the partial derivatives $\partial y_{m} / \partial x_{n} . \boldsymbol{S}_{y}$ is the measurement noise covariance matrix. The estimate $\hat{\boldsymbol{x}}$ of the vertical profile of the target variable can be calculated as

$\hat{\boldsymbol{x}}_{i+1}=\hat{\boldsymbol{x}}_{i}+\left(\boldsymbol{K}^{T} \boldsymbol{S}_{y}^{-1} \boldsymbol{K}+\lambda \boldsymbol{I}\right)^{-1} \boldsymbol{K}^{T} \boldsymbol{S}_{y}^{-1}\left(\boldsymbol{y}-F\left(\hat{\boldsymbol{x}}_{i}\right)\right)$,

where $i$ is the iteration number in a Newtonean iteration, and $F$ is the radiative transfer model used for simulation of the measurements. The term $\lambda \boldsymbol{I}$ limits the stepwidth of the iteration and pushes the correction vector $\boldsymbol{x}_{i+1}-\boldsymbol{x}_{i}$ towards the direction of the steepest gradient of the penalty function $(\boldsymbol{y}-F(\boldsymbol{x}))^{T} \boldsymbol{S}_{y}^{-1}(\boldsymbol{y}-F(\boldsymbol{x}))$ (Levenberg, 1944; Marquardt, 1963) but does not influence the solution in the case perfect numerical convergence is achieved. This term thus does not need to be cosidered in estimating the spatial response function of the retrieval. As most common limb retrieval schemes, Eq. (1) assumes local horizontal homogeneity of the atmosphere. The vertical averaging kernel of this kind of retrieval, i.e. the derivative of the estimated profile with respect to the true atmospheric state, sampled on the tangent altitude grid, is unity. The horizontal averaging kernels need some further investigation.

\section{Horizontal averaging kernels: theory}

In order to allow the assessment not only of hard-wired 1-D retrievals but also of retrievals where horizontal variability is subject to a soft constraint, we formulate this retrieval as a formal two-dimensional retrieval (altitude and along-track coordinate) where the assumption of horizontal homogeneity is implemented by a numerical constraint. For clarity, we omit all formalism related to the Newtonean iteration because this is unnecessary for retrieval diagnostics in the case of moderately nonlinear radiative transfer. We further assume that the lines of sight of the instrument lie in the orbit plane of the spacecraft, an assumption which is justified for major parts of the Envisat orbit (Carlotti et al., 2001):

$$
\begin{aligned}
\hat{\boldsymbol{x}}_{2 \mathrm{D}}= & \hat{\boldsymbol{x}}_{2 \mathrm{D}, 0} \\
& +\left(\boldsymbol{K}_{2 \mathrm{D}}^{T} \boldsymbol{S}_{y}^{-1} \boldsymbol{K}_{2 \mathrm{D}}+\boldsymbol{R}\right)^{-1} \boldsymbol{K}_{2 \mathrm{D}}^{T} \boldsymbol{S}_{y}^{-1}\left(\boldsymbol{y}-F\left(\boldsymbol{x}_{2 \mathrm{D}, 0}\right)\right)
\end{aligned}
$$

Here $\boldsymbol{x}_{2 \mathrm{D}}$ is the 2-dimensional representation of the atmospheric state, arranged in a column vector $\left(x_{1,1}, \ldots, x_{1, j}, x_{2,1}, \ldots, x_{2, j}, \ldots, x_{k, j}\right)^{T}$ where $k$ is the number of altitude gridpoints and $j$ is the number of horizontal gridpoints (in a geocentered angular coordinate). The Jacobian $\boldsymbol{K}_{2 \mathrm{D}}$ contains the derivatives of the signal with respect to the full 2-dimensional field of atmospheric state variables, as provided by radiative transfer codes supporting 2-dimensional radiative transfer and Jacobian calculation, e.g. the KOPRA model (Steck et al., 2005; Stiller, 2000; Stiller et al., 2002) or the forward model used in the GEOFIT (Carlotti et al., 2001) or the GMTR (Carlotti et al., 2006) retrieval codes. The $j k \times j k$ constraint matrix $\boldsymbol{R}$ is block-diagonal. Each diagonal block of the size $k \times k$ is calculated as $\gamma \boldsymbol{L}^{T} \boldsymbol{L}$ where $\boldsymbol{L}$ is a first order finite differences operator (Phillips, 1962; Tikhonov, 1963b,a; Twomey, 1963, 1965):

$\boldsymbol{L}=\left(\begin{array}{cccccc}-1 & 1 & 0 & \ldots & 0 & 0 \\ 0 & -1 & 1 & \ldots & 0 & 0 \\ & & & \ddots & & \\ 0 & 0 & 0 & \ldots & -1 & 1\end{array}\right)$

With the scalar tuning parameter $\gamma$ chosen large enough, all horizontal variation of the atmosphere is suppressed and a 1-dimensional profile retrieval is emulated within the 2dimensional retrieval formalism. Differentiation of Eq. (2) with respect to the the true atmospheric state $\boldsymbol{x}_{2 \mathrm{D}}$ gives the 2 dimensional averaging kernel of the 1-dimensional retrieval:

$\boldsymbol{A}_{2 \mathrm{D}}=\left(\boldsymbol{K}_{2 \mathrm{D}}^{T} \boldsymbol{S}_{y}^{-1} \boldsymbol{K}_{2 \mathrm{D}}+\boldsymbol{R}\right)^{-1} \boldsymbol{K}_{2 \mathrm{D}}^{T} \boldsymbol{S}_{y}^{-1} \boldsymbol{K}_{2 \mathrm{D}}$

The $k$ diagonal blocks of size $j \times j$ of the $k j \times k j$ averaging kernel are the horizontal averaging kernels of the retrieval. With $\gamma$ large enough to remove all horizontal variation, all the rows within such a block are identical. A row of a diagonal block can be used as horizontal observation operator at the respective altitude and can be used to characterize the horizontal smoothing of a standard 1-dimensional limb retrieval.

For hard-wired one-dimensional profile retrievals, the horizontal averaging kernel can be obtained in a more straight-forward manner simply by differentiating the onedimensional estimates (i.e. the vertical profile values) with respect to the variations of the true two-dimensional field of atmospheric state variables.

$\boldsymbol{A}_{\text {hor }}=\left(\boldsymbol{K}^{T} \boldsymbol{S}_{y}^{-1} \boldsymbol{K}\right)^{-1} \boldsymbol{K}^{T} \boldsymbol{S}_{y}^{-1} \boldsymbol{K}_{2 \mathrm{D}}$ 
Applied to hard-wired one-dimensional profile retrievals evaluated for a horizontally homogeneous atmosphere, the approaches Eq. (4) and Eq. (5) are equivalent with respect to the result but Eq. (5) is computationally more efficient. Results are different for averaging kernels evaluated for a nonhomogeneous atmosphere because non-homogeneity is considered in the Jacobian $\boldsymbol{K}_{2 D}$ of Eq. (4) but not in the Jacobian $\boldsymbol{K}$ used in Eq. (5). In such cases, the latter approach is appropriate to characterize hard-wired one-dimensional retrievals, while the former characterizes constrained two-dimensional retrievals.

\section{Application to MIPAS}

Horizontal averaging kernels have been calculated for the MIPAS key products (temperature and mixing ratios of $\mathrm{H}_{2} \mathrm{O}$, $\mathrm{O}_{3}, \mathrm{CH}_{4}, \mathrm{~N}_{2} \mathrm{O}, \mathrm{HNO}_{3}$ and $\mathrm{NO}_{2}$ ). These horizontal averaging kernels refer to MIPAS high spectral resolution $\left(0.025 \mathrm{~cm}^{-1}\right.$, unapodized) measurements that were acquired from July 2002 until March 2004. These calculations are based on Jacobians calculated with the KOPRA (Stiller, 2000) radiative transfer model with $50 \mathrm{~km}$ horizontal gridwidth and a vertical retrieval grid defined by the MIPAS nominal tangent altitudes $(6-42 \mathrm{~km}$ at 3-km stepwidth, additionally $47,52,60$ and $68 \mathrm{~km}$, reduced altitude range for some species). These calculations have been performed for a retrieval setup consistent with the MIPAS offline (OFL) data (Raspollini et al., 2006), which cover a wider altitude range and are based on a larger subset of the available tangent altitudes than the MIPAS near-real-time (NRT) data. Three atmospheric conditions have been investigated (Fig. 1), namely midlatitudinal, polar, and tropical (Kiefer et al., 2002). Unless explicitly mentioned, the Jacobians were evaluated for a horizontally homogeneous atmosphere. No numerical constraint has been applied in the vertical except that implied by the quite coarse retrieval grid.

We discuss the results with respect to three characteristics, namely information displacement, information spread, and impacts onto the profile shape. Numerical results for quantitative use are provided in the supplemental data (http://www.atmos-meas-tech.net/2/47/2009/ amt-2-47-2009-supplement.zip). In this paper we restrict the discussion to some typical sample cases.

\subsection{Information displacement}

The information displacement we define is the horizontal distance between the point where the most information comes from and the nominal geolocation of the limb scan, which is defined as the geolocation of the tangent point of the middle line of sight in a MIPAS limb scan. For a nominal MIPAS limb scan this is the geolocation of the $30-\mathrm{km}$ tangent point. The ESA online processor assumes local horizontal
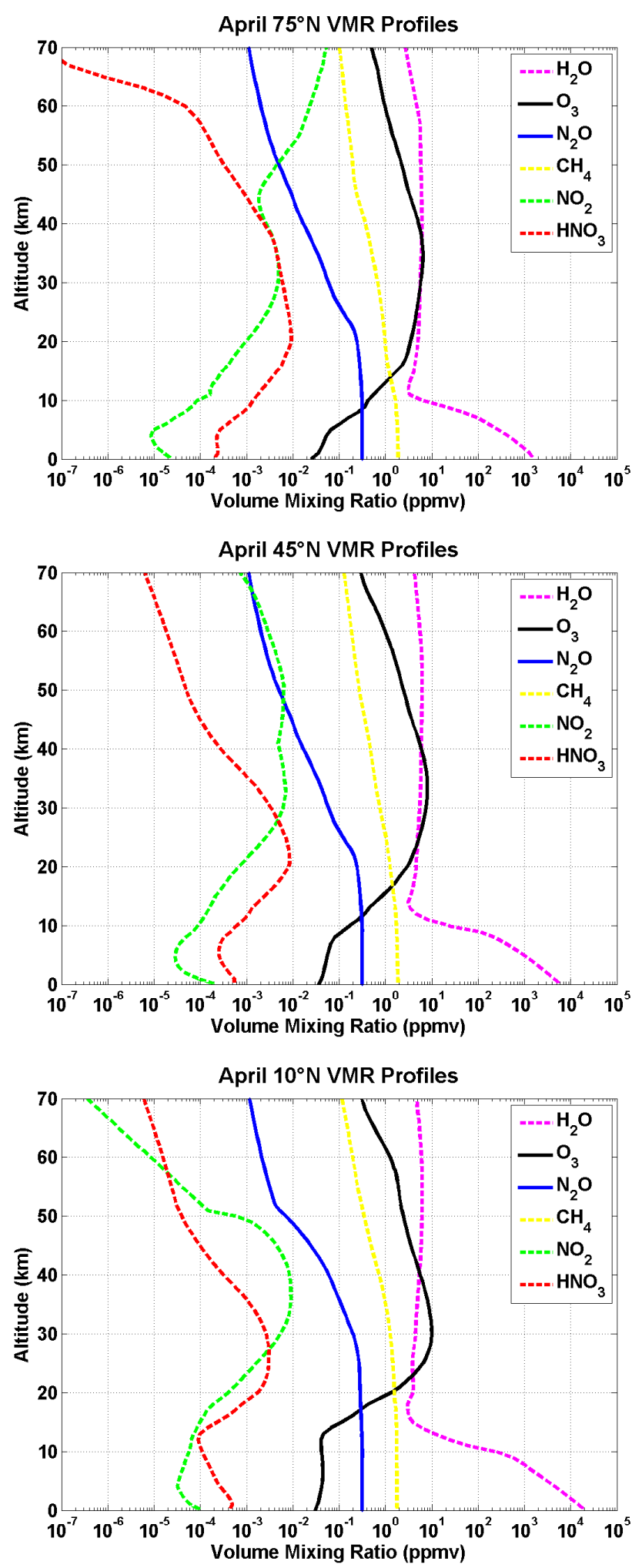

Fig. 1. Target species mixing ratio vertical profiles used in this study for polar (top panel), milatitude (middle panel) and tropic (lower panel) atmospheres. 


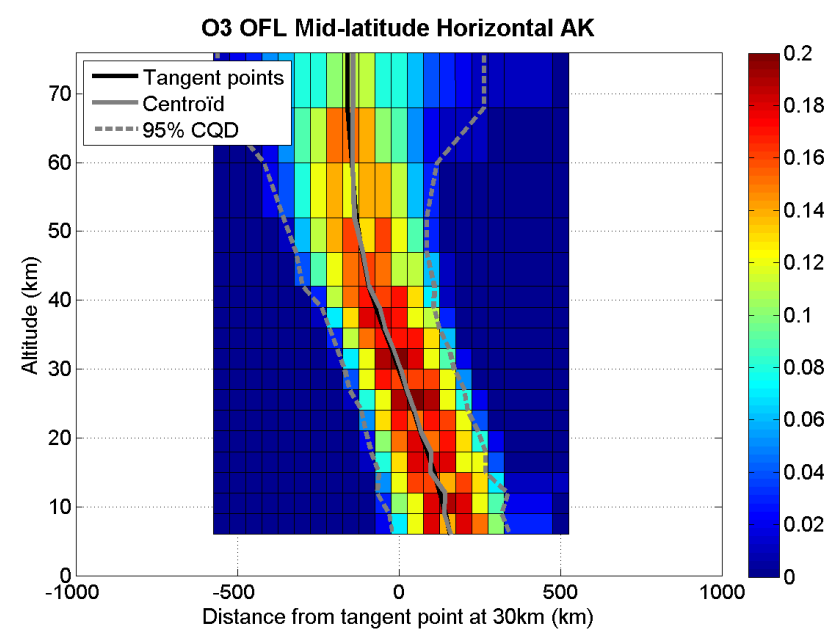

Fig. 2. MIPAS horizontal averaging kernel for $\mathrm{O}_{3}$, evaluated for a midlatitude homogeneous atmosphere. The black line is the position of the actual tangent points. The grey line is the centroid of the horizontal averaging kernel. $95 \%$ of the information originates from the region between the dashed lines. Negative distances are displacement towards beyond the tangent point, positive distances are displacement towards the satellite. Numeric data are found in the auxiliary files.

homogeneity and each retrieved profile is assigned to the nominal geolocation of the limb scan.

A part of the information displacement is explained by the observation geometry and the satellite movement, but radiative transfer effects and sampling density are also important in some cases. The information displacement can be calculated on the basis of the position of the centroid of the horizontal averaging kernel, its maximum or the median. All these quantifiers are reported in the supplemental data files (http://www.atmos-meas-tech.net/2/47/ 2009/amt-2-47-2009-supplement.zip).

The tangent point is displaced towards the satellite by $160 \mathrm{~km}$ for the lowermost nominal tangent altitude $(6 \mathrm{~km})$ and $159 \mathrm{~km}$ in the opposite direction for the uppermost nominal tangent altitude $(68 \mathrm{~km})$. This displacement is caused by the satellite movement $(\approx 510 \mathrm{~km}$ per limb scan $)$ and the position of the tangent point as a function of the elevation angle. Since MIPAS is rearward looking top down scanning, both effects in tendency compensate, with a net movement of the tangent point of about $320 \mathrm{~km}$ during one limb scan in flight direction. In most trace gas retrievals, this geometrically caused displacement explains the majority of the actual information displacement for all species and most altitudes. Figure 2 shows the $\mathrm{O}_{3}$ midlatitudes horizontal averaging kernels and may serve as a typical example. Besides this displacement due to measurement geometry, in most cases the information maximum is displaced slightly (typically less than $10 \mathrm{~km}$ ) towards the satellite. The latter is because weighting functions of a single line of sight through

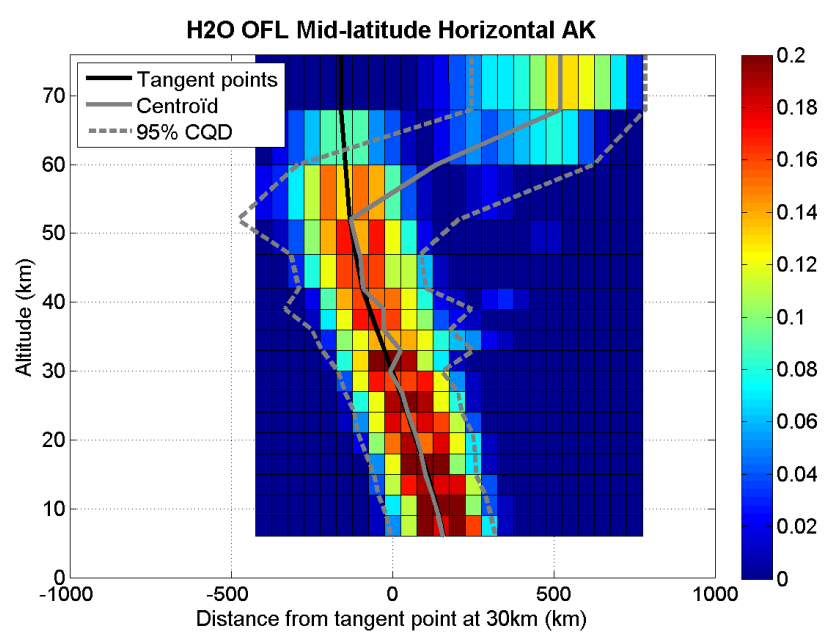

Fig. 3. MIPAS horizontal averaging kernel for $\mathrm{H}_{2} \mathrm{O}$, evaluated for a midlatitude homogeneous atmosphere. For details, see Fig. 2. Pronounced information displacement towards the satellite through saturized radiative transfer is visible for the uppermost altitudes.

a horizontally homogeneous atmosphere typically peak between the tangent point and the satellite because of the nonlinearity of radiative transfer. A longer optical path between the emitting air volume and the observing instrument goes along with more absorption of the signal. The only exceptions are $\mathrm{H}_{2} \mathrm{O}$ (all atmospheres) and $\mathrm{CH}_{4}$ (tropical and midlatitudinal atmospheres) at the uppermost altitude of $68 \mathrm{~km}$. Since the particular retrieval scheme under assessment scales the a priori profiles above the uppermost tangent altitude instead of attempting to obtain independent profile information, this altitude represents the information about the entire atmosphere between $68 \mathrm{~km}$ and the top of the atmosphere, (c.f. Ridolfi et al., 2000; Raspollini et al., 2006). In these particular cases the peak of information is displaced by up to about $510 \mathrm{~km}$ towards the satellite (Fig. 3). This is because in these cases the information gained through emission of radiance near the tangent point is outweighted by absorption in higher, colder atmospheric layers. This effect is particularly large in cases of non-linear radiative transfer in an atmosphere of large opacity in the given spectral region.

In some cases, however, the majority of information of MIPAS profile retrievals originates from the atmosphere slightly beyond the actual tangent point, e.g. for daytime tropical $\mathrm{NO}_{2}$ at 42 and $50 \mathrm{~km}$ altitude (Fig. 4). While the argument of nonlinear radiative transfer certainly holds for each single MIPAS limb scan, this effect can sometimes be overcompensated for all but the lowermost tangent altitudes by the following geometrical effects: First, the MIPAS field of view is finite and covers about $3 \mathrm{~km}$ in the vertical at the tangent point. This means that beyond the tangent point the fields of view of measurements at adjacent tangent altitudes are overlapping, leading to multiple sampling of air masses beyond the tangent point. This effect accounts for a backward 


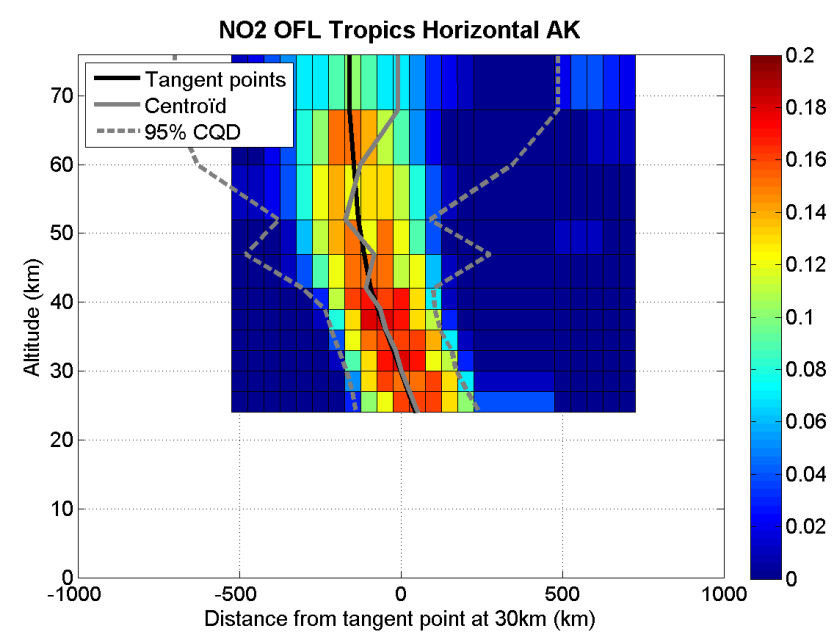

Fig. 4. MIPAS horizontal averaging kernel for $\mathrm{NO}_{2}$, evaluated for a tropical daytime homogeneous atmosphere. For details, see Fig. 2. Some minor information displacement towards beyond the tangent point is visible near 42 and $50 \mathrm{~km}$ altitude.

displacement of the median point by $1-7 \mathrm{~km}$. Moreover, the interaction between satellite movement and downward scanning contributes to this effect: While a limb sequence of spectra is recorded top down, i.e. from the uppermost to the lowermost tangent altitude, Envisat moves about $510 \mathrm{~km}$ in the opposite of the viewing direction. This leads, during one single limb scan, to denser sampling of the atmosphere beyond the tangent points than satellite-side of the tangent point. Through the satellite motion, the points where the raypaths of a limb scan intersect a certain altitude level move together beyond the tangent point, while they diverge on the satellite side of the tangent point. As a consequence, the retrieval uses more information per latitude increment from beyond the tangent point (c.f. Fig. 3, $30 \mathrm{~km}$ altitude). This explanation has been verified by a test retrieval where the satellite was assumed stationary and where this information displacement effect has not been observed. Due to its small effect, however, this issue is of purely academic interest.

For temperature the situation is slightly different: Most information on temperature originates from a point displaced from the actual tangent point towards the satellite by about 50 to $100 \mathrm{~km}$ (Fig. 5). This is because at the spectral intervals used for temperature retrieval the atmosphere is far less transparent than at those used for trace gas abundance retrievals. This is an issue not only because the temperature information is inaccurately assigned to its true geolocation but also because this can trigger a systematic error when retrieved temperatures are subsequently used for trace gas retrievals. While this kind of error is included in the error budget of the MIPAS-OFL data (Raspollini et al., 2006), other MIPAS data processors account for this problem by retrieving a horizontal temperature gradient jointly with the temperature and elevation pointing and using this

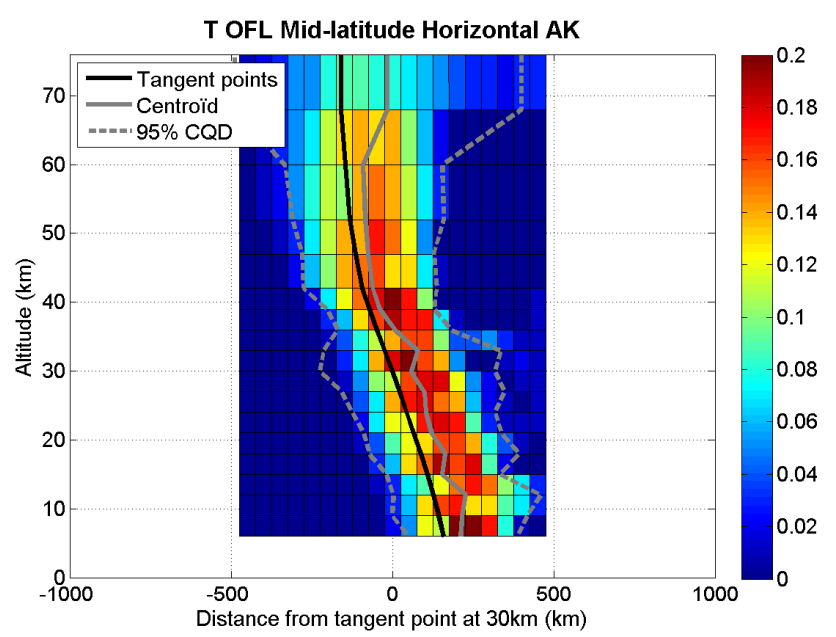

Fig. 5. MIPAS horizontal averaging kernel for temperature, evaluated for a midlatitude homogeneous atmosphere. For details, see Fig. 2. There is a systematic information displacement of 50$100 \mathrm{~km}$ towards the satellite.

gradient information for subsequent trace gas retrievals (c.f. http://www.fzk.de/imk/asf/sat/envisat-data).

\subsection{Information spread}

The information spread is a measure of the horizontal smearing of the retrieval. We report the spread in terms of both the half-width (full width at half maximum, FWHM) and various centered quantile distances (CQD), namely $50 \%, 68 \%$, $95 \%$, and $99 \%$. The $x \%$ CQD is the distance between the $x+(1-x) / 2$ and the $(1-x) / 2$ quantiles and indicates the horizontal region $x$ percent of information originates from.

The FWHM of the horizontal averaging kernel generally increases with altitude. It ranges from $210 \mathrm{~km}\left(\mathrm{CH}_{4}\right.$, tropical atmosphere) to $330 \mathrm{~km}\left(\mathrm{NO}_{2}\right.$, tropical atmosphere daytime) at $6 \mathrm{~km}$ tangent altitude. The respective 95\% CQDs are $262 \mathrm{~km}$ and $382 \mathrm{~km}$. For $52 \mathrm{~km}$ tangent altitude, it ranges from $315 \mathrm{~km}\left(\mathrm{H}_{2} \mathrm{O}\right.$, midlatitudes) to $387 \mathrm{~km}\left(\mathrm{~N}_{2} \mathrm{O}\right.$, polar atmosphere), with related 95-\% CQDs of $683 \mathrm{~km}\left(\mathrm{H}_{2} \mathrm{O}\right.$, midlatitudes) and $478 \mathrm{~km}\left(\mathrm{~N}_{2} \mathrm{O}\right.$, polar atmosphere). The FWHM is somewhere between the 68-\% and the 95-\% CQDs in most cases. Compared to the MIPAS along-track sampling, which is about $510 \mathrm{~km}$, the horizontal smearing in terms of FWHM often is a factor of about 2 smaller. That means that the atmosphere is horizontally undersampled even in the along-track direction. In consequence, small-scale periodic phenomena are prone to aliasing.

\subsection{Impact of horizontal smoothing on profile information}

In order to assess if the horizontal smoothing error triggers profile errors, in other words, to find out if the hard constraint of horizontal homogeneity causes profile errors, we 
O3 OFL Mid-Latitude Horizontal AK with $1 \mathrm{~K} / 100 \mathrm{~km}$ T gradient

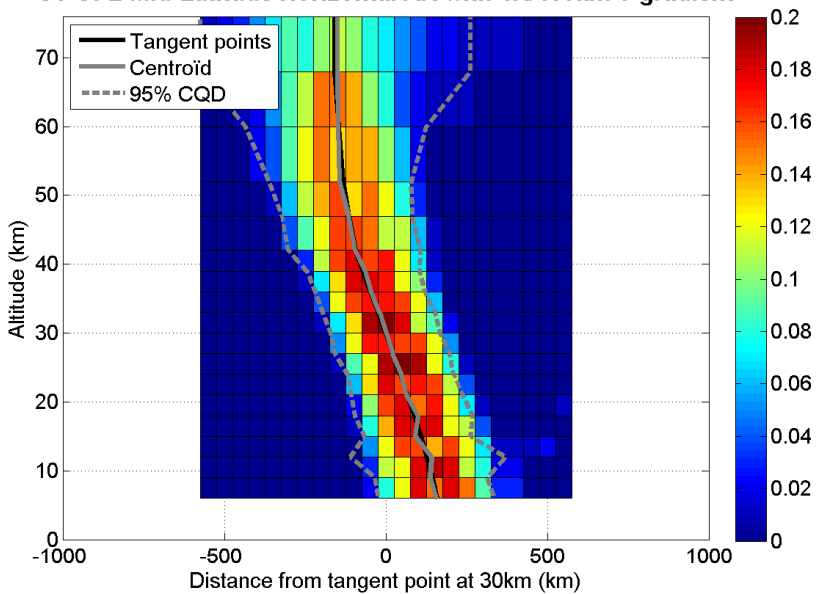

Fig. 6. MIPAS horizontal averaging kernel for $\mathrm{O}_{3}$, evaluated for a midlatitude atmosphere with a meridional temperature gradient of $1 \mathrm{~K} / 100 \mathrm{~km}$, warmer towards South. For details, see Fig. 2.

have calculated the horizontally integrated averaging kernel $\tilde{\boldsymbol{A}}$ with the elements

$\tilde{a}_{k, n}=\sum_{i=1}^{j} a_{i ; k, n}$

where $k$ and $n$ are the altitude indices and $i$ is the horizontal index of the element $a$ of $\boldsymbol{A}_{\text {hor }}$. $\tilde{\boldsymbol{A}}$ was found to equal the identity matrix at at least three digits. This confirms expectations that within linear estimation no profile error is triggered by horizontal smoothing and verifies the implementation of the method.

4.4 Averaging kernels evaluated for horizontally nonhomogeneous atmospheres

The horizontal averaging kernels discussed above were evaluated for horizontally homogeneous atmospheres. One might expect different behaviour of retrievals in horizontally inhomogeneous atmospheres. Temperature is a particularly critical parameter whose horizontal gradients may largely affect radiative transfer. Horizontal gradients in interfering trace species are supposed to have small influence due to efficient microwindow selection, where interferences by nontarget species are minimized. Thus we have, as a kind of estimate for a particularly difficult case, evaluated the horizontal averaging kernel for a midlatitudinal ozone retrieval in an atmosphere with an along-line-of-sight temperature gradient of $1 \mathrm{~K} / 100 \mathrm{~km}$, increasing from North to South. Results do not largely differ from those evaluated for the horizontally homogeneous atmosphere (Fig. 6). The FWHM is smaller by less than $2.5 \%$, and the center of information is moved by only about $5 \mathrm{~km}$ off the satellite.

As a worst case, we have also investigated the horizontal averaging kernel evaluated for an atmosphere with a horizon-

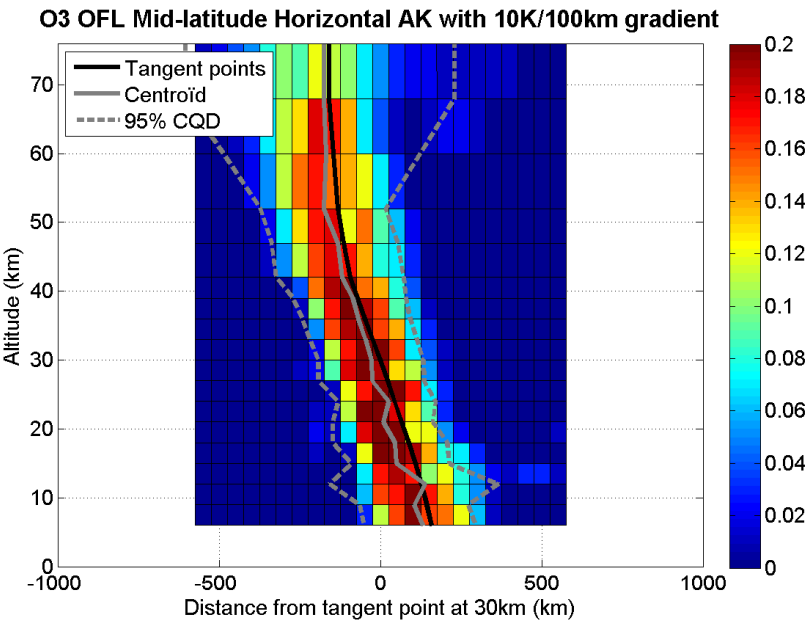

Fig. 7. MIPAS horizontal averaging kernel for $\mathrm{O}_{3}$, evaluated for a meridional temperature gradient of $10 \mathrm{~K} / 100 \mathrm{~km}$, applicable over a range of $400 \mathrm{~km}$, warmer towards South. For details, see Fig. 2.

tal temperature gardient of $10 \mathrm{~K} / 100 \mathrm{~km}$, applicable over a range of $400 \mathrm{~km}$ around the nominal geolocation of the limb scan, i.e. with a maximum temperature difference of $40 \mathrm{~K}$ between the colder foreground and the warmer background. While the information spread is not significantly affected, there is an information displacement of about $50 \mathrm{~km}$ towards the background (Fig. 7). Due to higher temperatures beyond the tangent point, radiance contributions and thus Jacobians are larger there.

We conclude that it is justified to use the averaging kernels evaluated for homogeneous atmospheres as approximative averaging kernels for the true atmospheric state, unless extreme horizontal temperature gradients are analyzed using models with horizontal gridwidth approaching $50 \mathrm{~km}$.

\section{Conclusions}

The horizontal MIPAS averaging kernels indicate the region where the retrieved profile information originates from and describe the horizontal smoothing of a retrieval which assumes local horizontal homogeneity of the atmospheric state. The latitudinal smearing of information is surprisingly small (below about $380 \mathrm{~km}$ in terms of FWHM, below about $500 \mathrm{~km}$ in terms of CQD except for the uppermost altitudes) and is considerably smaller than the horizontal sampling (ca. $510 \mathrm{~km}$ ) which is defined by the horizontal distance between two adjacent limb scans. This means that the atmosphere is not continuously sampled by the MIPAS nominal high resolution measurement scenario. A potential consequence of this along-track undersampling and missing physical low-pass filtering by the measurement geometry is the risk of aliasing effects even in the along-track direction when small scale wave structures are analyzed. 
The horizontal MIPAS averaging kernels can be used to construct the along-track components of observation operators for data assimilation purposes. The low horizontal sampling width allows to disregard the horizontal smearing effects of MIPAS for all assimilation or model comparison applications where the horizontal gridwidth is larger than about $300 \mathrm{~km}$. For many of these applications, it will be sufficient to just consider the information displacement relative to the nominal geolocation of the MIPAS limb scan. With a few exceptions, the horizontal displacement is dominated by the displacement of the tangent point with respect to the nominal geolocation of the limb scan, while other effects (nonlinearity of radiative transfer, overlapping fields of view behind the tangent point, and denser sampling behind the tangent point) play a minor role, except for temperature, where the information is displaced by $50-100 \mathrm{~km}$ from the actual tangent point towards the satellite. In the cross-track domain, MIPAS data can be interpolated like point-measurements unless the model gridwidth approaches values as low as $30 \mathrm{~km}$, which is the horizontal width of the instantaneous field of view of MIPAS.

While the numerical values presented here are MIPAS instrument-specific, and even depend on the MIPAS measurement scenario (results shown here refer to the nominal high spectral resolution measurement mode), the methods to calculate the horizontal averaging kernels can be applied to each limb sounding emission or occultation instrument with lines of sight approximately in the orbit plane, and, with straight-forward modifications, also to any other limb sounding instrument. An application of this approach to constrained retrievals is found in von Clarmann et al. (2009).

Acknowledgements. This work has been funded by EC FP6 Integrated Project GEOMon (contract 036677), ProDEx project SECPEA and ESA MIPAS QWG.

Edited by: C. von Savigny

\section{References}

Carlotti, M.: Global-fit approach to the analysis of limb-scanning atmospheric measurements, Appl. Optics, 27, 3250-3254, 1988.

Carlotti, M., Dinelli, B. M., Raspollini, P., and Ridolfi, M.: Geofit approach to the analysis of limb-scanning satellite measurements, Appl. Optics, 40, 1872-1885, 2001.

Carlotti, M., Brizzi, G., Papandrea, E., Prevedelli, M., Ridolfi, M., Dinelli, B. M., and Magnani, L.: GMTR: Two-dimensional geofit multitarget retrieval model for Michelson Interferometer for Passive Atmospheric Sounding/ Environmental Satellite observations, Appl. Optics, 45, 716-727, 2006.

Dudhia, A., Jay, V. L., and Rodgers, C. D.: Microwindow selection for high-spectral-resolution sounders, Appl. Optics, 41, 36653673, 2002.

Fischer, H., Birk, M., Blom, C., Carli, B., Carlotti, M., von Clarmann, T., Delbouille, L., Dudhia, A., Ehhalt, D., Endemann, M., Flaud, J. M., Gessner, R., Kleinert, A., Koopman, R., Langen, J.,
López-Puertas, M., Mosner, P., Nett, H., Oelhaf, H., Perron, G., Remedios, J., Ridolfi, M., Stiller, G., and Zander, R.: MIPAS: an instrument for atmospheric and climate research, Atmos. Chem. Phys., 8, 2151-2188, 2008,

http://www.atmos-chem-phys.net/8/2151/2008/.

Goldman, A. and Saunders, R. S.: Analysis of Atmospheric Infrared Spectra for Altitude Distribution of Atmospheric Trace Constituents - I. Method of Analysis, J. Quant. Spectrosc. Radiat. Transfer, 21, 155-161, 1979.

Ide, K., Courtier, P., Ghil, M., and Lorenc, A. C.: Unified notation for data assimilation: Operational, sequential and Variational, J. Meteorol. Soc. Jpn., 75, 181-189, 1997.

Kiefer, M., von Clarmann, T., and Grabowski, U.: State parameter Data Base for MIPAS Data Analysis, Adv. Space Res., 30, 23872392, 2002.

Lahoz, W. A., Geer, A. J., Bekki, S., Bormann, N., Ceccherini, S., Elbern, H., Errera, Q., Eskes, H. J., Fonteyn, D., Jackson, D. R., Khattatov, B., Marchand, M., Massart, S., Peuch, V.-H., Rharmili, S., Ridolfi, M., Segers, A., Talagrand, O., Thornton, H. E., Vik, A. F., and von Clarmann, T.: The Assimilation of Envisat data (ASSET) project, Atmos. Chem. Phys., 7, 1773-1796, 2007 ,

http://www.atmos-chem-phys.net/7/1773/2007/.

Levenberg, K.: A method for the solution of certain non-linear problems in least squares, Quart. Appl. Math., 2, 164-168, 1944.

Marquardt, D. W.: An algorithm for least-squares estimation of nonlinear parameters, J. Soc. Indust. Appl. Math., 11, 431-441, 1963.

McKee, T. B., Whitman, R. I., and Lambiotte Jr., J. J.: A Technique to Infer Atmospheric Water-Vapor Mixing Ratio from Measured Horizon Radiance Profiles, Tech. Rep. TN D-5252, NASA, Washington, D.C., 1969.

Mill, J. D. and Drayson, S. R.: A nonlinear technique for inverting limb absorption profiles, Developments in Atmospheric Science, 9, 123-135, 1978.

Phillips, D.: A Technique for the numerical solution of certain integral equations of first kind, J. Ass. Comput. Mat., 9, 84-97, 1962.

Raspollini, P., Belotti, C., Burgess, A., Carli, B., Carlotti, M., Ceccherini, S., Dinelli, B. M., Dudhia, A., Flaud, J.-M., Funke, B., Höpfner, M., López-Puertas, M., Payne, V., Piccolo, C., Remedios, J. J., Ridolfi, M., and Spang, R.: MIPAS level 2 operational analysis, Atmos. Chem. Phys., 6, 5605-5630, 2006, http://www.atmos-chem-phys.net/6/5605/2006/.

Ridolfi, M., Carli, B., Carlotti, M., von Clarmann, T., Dinelli, B., Dudhia, A., Flaud, J.-M., Höpfner, M., Morris, P. E., Raspollini, P., Stiller, G., and Wells, R. J.: Optimized Forward and Retrieval Scheme for MIPAS Near-Real-Time Data Processing, Appl. Optics, 39, 1323-1340, 2000.

Ridolfi, M., Blum, U., Carli, B., Catoire, V., Ceccherini, S., Claude, H., De Clercq, C., Fricke, K. H., Friedl-Vallon, F., Iarlori, M., Keckhut, P., Kerridge, B., Lambert, J.-C., Meijer, Y. J., Mona, L., Oelhaf, H., Pappalardo, G., Pirre, M., Rizi, V., Robert, C., Swart, D., von Clarmann, T., Waterfall, A., and Wetzel, G.: Geophysical validation of temperature retrieved by the ESA processor from MIPAS/ENVISAT atmospheric limb-emission measurements, Atmos. Chem. Phys., 7, 4459-4487, 2007, http://www.atmos-chem-phys.net/7/4459/2007/. 
Rodgers, C. D.: Inverse Methods for Atmospheric Sounding: Theory and Practice, in: Series on Atmospheric, Oceanic and Planetary Physics, Vol. 2, edited by: Taylor, F. W., World Scientific, 2000 .

Steck, T., Höpfner, M., von Clarmann, T., and Grabowski, U.: Tomographic retrieval of atmospheric parameters from infrared limb emission observations, Appl. Optics, 44, 3291-3301, 2005.

Stiller, G. P. (Ed.): The Karlsruhe Optimized and Precise Radiative Transfer Algorithm (KOPRA), in: Wissenschaftliche Berichte, Vol. FZKA 6487, Forschungszentrum Karlsruhe, 2000.

Stiller, G. P., von Clarmann, T., Funke, B., Glatthor, N., Hase, F., Höpfner, M., and Linden, A.: Sensitivity of trace gas abundances retrievals from infrared limb emission spectra to simplifying approximations in radiative transfer modelling, J. Quant. Spectrosc. Radiat. Transfer, 72, 249-280, 2002.

Tikhonov, A.: On the solution of incorrectly stated problems and method of regularization, Dokl. Akad. Nauk. SSSR, 151, 501504, 1963a.

Tikhonov, A.: On the regularization of incorrectly stated problems, Dokl. Akad. Nauk. SSSR, 153, 49-52, 1963b.
Twomey, S.: On the Numerical Solution of Fredholm Integral Equations of the First Kind by the Inversion of the Linear System Produced by Quadrature, Journal of the ACM, 10, 97-101, 1963.

Twomey, S.: The Application of Numerical Filtering to the Solution of Integral Equations Encountered in Indirect Sensing Measurements, Journal of the Franklin Institute, 279, 95-109, 1965.

von Clarmann, T., Glatthor, N., Grabowski, U., Höpfner, M., Kellmann, S., Kiefer, M., Linden, A., Mengistu Tsidu, G., Milz, M., Steck, T., Stiller, G. P., Wang, D. Y., Fischer, H., Funke, B., Gil-López, S., and López-Puertas, M.: Retrieval of temperature and tangent altitude pointing from limb emission spectra recorded from space by the Michelson Interferometer for Passive Atmospheric Sounding (MIPAS), J. Geophys. Res., 108, 4736, doi:10.1029/2003JD003602, 2003.

von Clarmann, T., Höpfner, M., Kellmann, S., Linden, A., Chauhan, S., Funke, B., Grabowski, U., Glatthor, N., Kiefer, M., Schieferdecker, T., Stiller, G. P., and Versick, S.: Retrieval of temperature, $\mathrm{H}_{2} \mathrm{O}, \mathrm{O}_{3}, \mathrm{HNO}_{3}, \mathrm{CH}_{4}, \mathrm{~N}_{2} \mathrm{O}, \mathrm{ClONO}_{2}$ and $\mathrm{ClO}$ from $\mathrm{MI}-$ PAS reduced resolution nominal mode limb emission measurements, Atmos. Meas. Tech. Discuss., 2, 181-236, 2009. 